\title{
Low Cost Rotor Fault Detection System for Inverter Driven Induction Motor
}

\author{
Namhun $\mathrm{Kim}^{\dagger}$ and Changho Choi*
}

\begin{abstract}
In this paper, the induction motor rotor fault diagnosis system using current signals, which are measured using axis-transformation method, and speed, which is estimated using current information, are presented. In inverter-fed motor drives unlike line-driven motor drives the stator currents have numerous harmonics components and therefore fault diagnosis using stator currents is very difficult. The current and speed signal for rotor fault diagnosis needs to be precise. Also, high resolution information, which means the diagnosis system, demands additional hardware such as low pass filter, high resolution ADC, encoder and etc. Therefore, the proposed axis-transformation and speed estimation method are expected to contribute to low cost fault diagnosis systems in inverter-fed motor drives without the need for an encoder and any additional hardware. In order to confirm validity of the developed algorithms, various experiments for rotor faults are tested and the line current spectrum of each faulty situation using Park transformation and speed estimation method are compared with the results obtained from fast Fourier transforms.
\end{abstract}

Keywords : Currents signal, Fault diagnosis, Induction motor, Inverter driven system, Rotor fault

\section{Introduction}

In recent years, marked improvement based on the development of micro processors and power electronics has been achieved in motor drives. However, motors driven by solid state inverters have undergone serious voltage stresses because of rapid switch-on and switch-off voltage of semiconductor devices. As a result, condition monitoring and incipient fault detection technology have become an important research area in recent years to prevent systems from sudden shut-downs because of significant motor faults in the industrial manufacturing facilities. In some factories, in order to prevent unexpected motor failures, a very expensive and regular maintenance is performed using high-priced instruments. Therefore, there is a considerable demand to reduce maintenance costs and prevent motor systems from unscheduled downtime. Over the past several decades substantial researches have been performed for new condition monitoring techniques for line-driven and inverter-driven motor drives.

Among fault diagnosis techniques, analyzing vibration signal with accelerometers, air-gap flux measurement with search coil, and thermal analysis provide satisfactory results [1-6]. Nevertheless these methods usually need extra high priced sensors as well as precious instruments

\footnotetext{
$\uparrow$ Corresponding Author: School of Electronic and Information Engineering, Cheongju University, Korea (nhkim@cju.ac.kr)

* POSCON R\&D Center, Korea (choi97@poscon.co.kr)

Received 10 May 2007 ; Accepted 27 September 2007
}

and wiring systems for transmitting/receiving the signals, making these fault diagnosis techniques very costly systems. New and promising research in the area of motor fault detection could be explored using the expert systems, artificial neural networks (ANNs), fuzzy systems, and genetic algorithms (GAs) $[7,8]$ and adaptive neuron-fuzzy inference systems (ANFIS) [9]. But to extract normal and fault characteristics, these techniques require offline or online training of diagnosis algorithms through simulations or experiment results. These techniques also need sophisticated computational procedures.

Therefore, simple and low cost protection without the usage of additional sensors and instruments is the most attractive means for industrial applications. The motor line current information of inverter fed motors is already available for control and protection purposes. Thus, by utilizing the current sensor feedback combined with the axis-transformation method for specific frequency component and speed estimation instead of FFT (Fast Fourier Transformation), the new algorithms for low-cost protection applications are achieved without using an encoder or any external hardware.

Although rotor faults are very commonly reported, with an occurrence of $5-10 \%[10,11]$, rotor fault detection of induction motors fed by inverters has not been investigated in the literature.

Thus, in this work, in order to detect broken rotor bar signal clarity using $12 \mathrm{bit}$ ADC, park transformation of measured currents and speed estimation are investigated theoretically and experimentally for inverter driven 
motors. To verify the proposed algorithms, a $2.2 \mathrm{~kW}$ induction and a TMS320C2812 DSP is used, and the V/F control method is adapted.

\section{Rotor Fault}

Fig. 1 shows the results of motor defection conducted by an EPRI and IEEE study. The study is carried out on the basis of opinion as reported by the motor manufacturer. In Fig. 1, the reasons for motor faults are classified by bearing faults, stator faults, rotor faults, and others and it shows that rotor defection percentage is around $9 \%$.

There are several reasons that cause rotor defections and these causes are shown below.

$\checkmark$ Thermal stress, hot spot or excessive losses, sparking caused by unbalance and overload.

$\checkmark$ Magnetic stress due to electromagnetic forces, unbalanced magnetic pull (UMP), electromagnetic noise, and vibration.

$\checkmark$ Residual stress produced by manufacturing problems.

$\checkmark$ Dynamic stress due to shaft torque, centrifugal forces, and cyclic stress.

$\checkmark$ Environmental stress caused by abrasion of rotor material or contamination.

$\checkmark$ Mechanical stresses produced by loose lamination, fatigued parts, and bearing failure.

For detection of rotor bar faults [11], [12], [13], and [14] employed the use of spectrum analysis of machine line currents, and in these papers sideband component
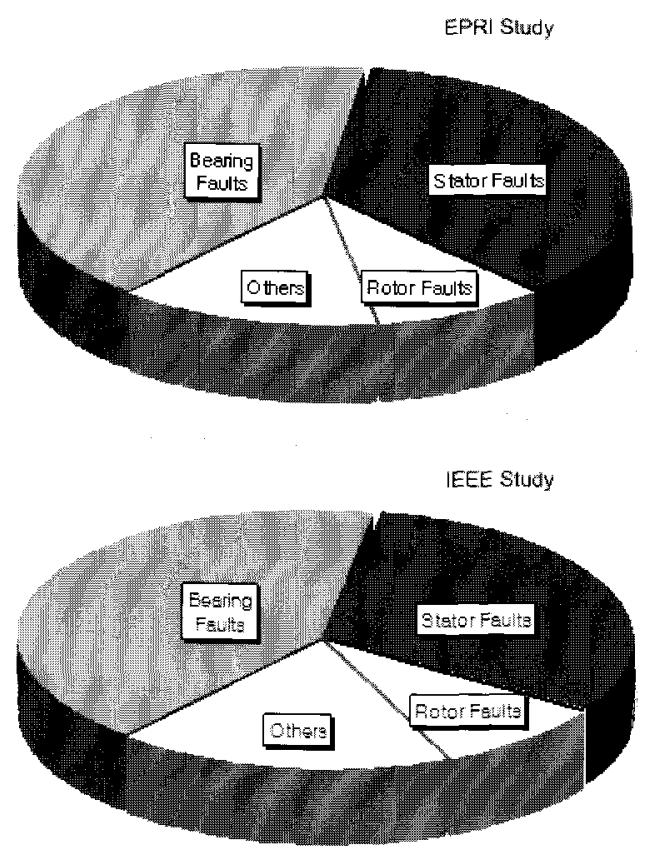

Fig. 1. Results of motor defection. $\left(f_{b}\right)$ is investigated, which is around the fundamental currents component for broken bar faults. The equation is below.

$$
f_{b}=(1 \pm 2 s) f
$$

Where, $s$ is slip, $\mathrm{f}$ is supply frequency, and $f_{b}$ is detectable broken rotor bar frequency.

While the lower sideband frequency presents a broken rotor bar, the upper sideband frequency is due to consequent speed oscillation. [13] shows that a broken bar gives rise to a sequence of sidebands given by (2)

$$
f_{b}=(1 \pm 2 \cdot k \cdot s) f
$$

Where, $k=1,2,3, \cdots$

\section{Proposed Algorithms and System Configuration}

In order to calculate specific frequency component, generally the FFT (Fast Fourier Transform) method is used, but the FFT method needs considerable calculation time, sophisticated algorithms, and much memory. Therefore, in this paper axis transformation, park transformation, and speed estimation methods using current signal and look up table, which are very simple and effective methods, are presented to estimate exact sideband currents frequency components.

Axis transformation method is a park transformation that makes a.c. to d.c. value conversion possible. With axis transformation against specific frequency, a.c. component and d.c. component are decoupled, i.e. if axis transformation is employed, the a.c. component (which is

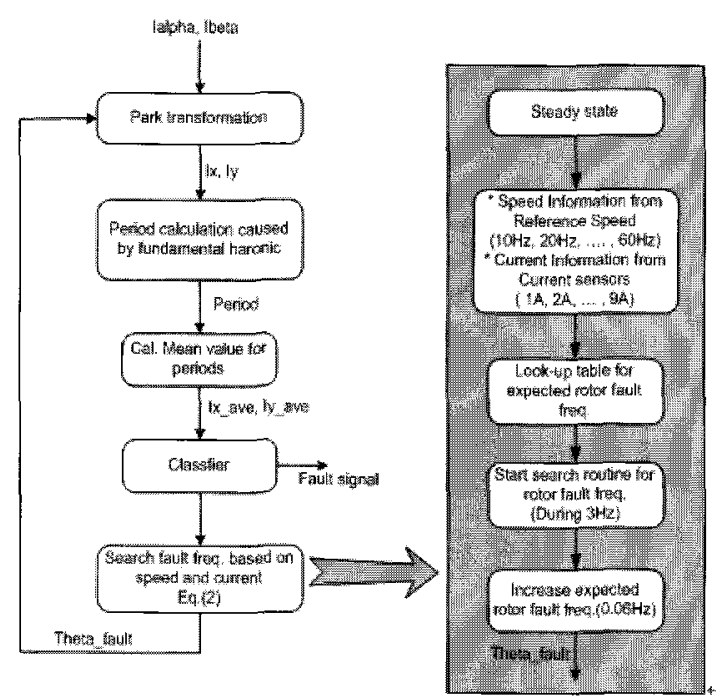

Fig. 2. Block diagram of the proposed method 


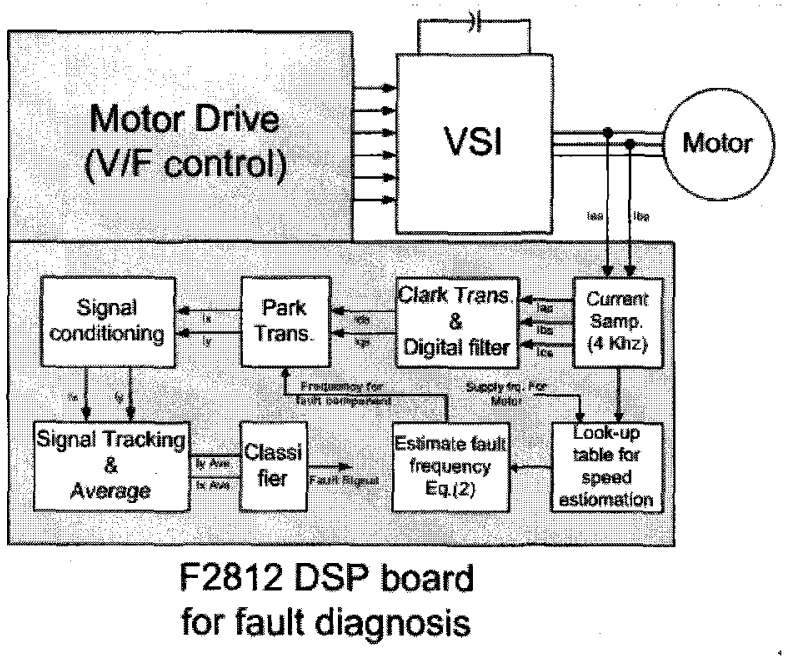

Fig. 3. System configuration.

expressed in the stationary reference frame) is transformed into a new rotation reference frame, which rotates together with a selected frequency component expected to cause broken rotor bar and a.c. expected noise value. Therefore, axis transformation makes calculation of specific frequency component very easy and effective.

Fig. 2 shows a block diagram of the proposed method. Through park transformation, a.c. currents component and d.c. currents component are decoupled, and to calculate exact d.c. component value expected to cause broken rotor fault estimate mean value for several periods. Based on previous process, ix_ave and iy_ave are calculated, and by means of classifier status of rotor is determined.

Fig. 3 shows the overall system configuration for rotor fault diagnosis. The inverter control and fault diagnosis system is implemented on the TMS320F2812 digital signal processor board from Texas Instruments. Various blocks used in the rotor bar fault diagnosis package are shown in this figure. Through the 12 bit on-chip ADC the current signals for motor control and fault diagnosis is collected with $4 \mathrm{kHz}$ sampling frequency. Using the clark transformation and digital filter the raw current signals are transferred. To calculate the fundamental frequency and the specific frequency component, which is the expected fault component caused by the broken rotor bar, the Park transformation, signal conditioning, signal tracking, and calculation of the average values of the classifier and fault frequency estimation block are used. Each part in Fig. 3 is shown below

A. Clarke trans. \& Digital Filter: Using measured three-phase currents of motor and clark transformation, real part current, $I_{\alpha}$ and imaginary part current, $I_{\beta}$, can be calculated, using Eq.(3) and Eq.(4). Also, a digital filter, which is a low pass filter, is used to reduce unwanted noise.

$$
\begin{gathered}
I_{\alpha}=I_{a s} \\
I_{\beta}=\left(I_{a s}+2 \times I_{b s}\right) / \sqrt{3}
\end{gathered}
$$

B. Park Trans.: This module is used to transfer a specific frequency component, which is expected to cause fault, to d.c. value, but other frequency components should be remained as a.c. values. Equations used for this transformation are (5) and (6).

$$
\begin{aligned}
& I_{x}=I_{\alpha} \times \cos \left(\theta_{\text {fault }}\right)+I_{\beta} \times \sin \left(\theta_{\text {faut }}\right) \\
& I_{y}=-I_{\alpha} \times \sin \left(\theta_{\text {fault }}\right)+I_{\beta} \times \cos \left(\theta_{\text {fault }}\right)
\end{aligned}
$$

C. Signal Conditioning: Park transformed Ix and Iy have a.c. value and d.c. value simultaneously. So we need to calculate only the d.c. component. In this module, the period caused by the fundamental component is estimated to remove the a.c. component.

D. Signal Tracking \& Average: In this module the average values of $\mathrm{Ix}$ and Iy, Ix ave and Iy ave, are calculated for several periods, which are coming from the Signal conditioning module, and the a.c. component that is contained in Iy and Ix, is removed. In other words,

$$
\begin{gathered}
\text { If } f_{x}=f_{a c}+f_{d c}, \\
\text { then } \frac{\sum_{n=1}^{k} f_{a c}+f_{d c}}{k}=f_{d c_{-} a v e}
\end{gathered}
$$

Where, $\mathrm{k}=$ (period for a.c. component) / (sampling time)

E. Speed estimation: Fig. 4 demonstrates torque/speed curve for an induction motor. For an induction motor driven by V/F control, feed-forward control, motor speed depends on load torque. A certain load torque is supplied to the running induction motor and motor speed will vary from $w_{1}$ to $w_{2}$. This region is almost proportional to the

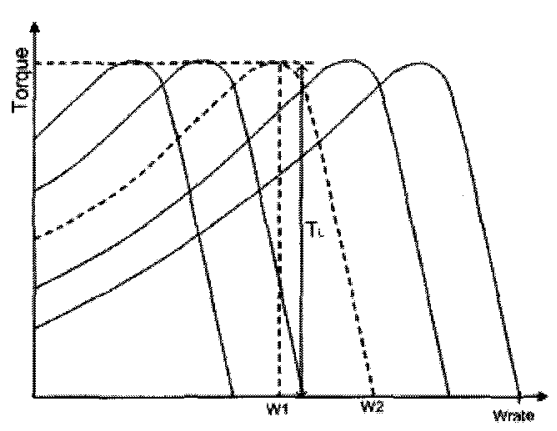

Fig. 4. Induction motor torque/speed curve 
stator currents. With this simple idea, speed estimation is performed. According to each frequency speed variation depending on stator current, amplitudes are measured and a look-up table for speed estimation is built.

Furthermore, in the case of the proposed fault detection algorithm it is not necessary to use the exact frequency that is expected to cause rotor fault, because fault detection algorithms are searching for $3[\mathrm{~Hz}]$ and analyzing the fault frequency.

\section{Experimental Results}

In order to verify the proposed algorithms, which is axis transformation to detect specific frequency component, experiments are performed. At the FFT analysis, it is very difficult to detect sideband component because FFT requires much data and it takes a lot of time to analyze frequency.

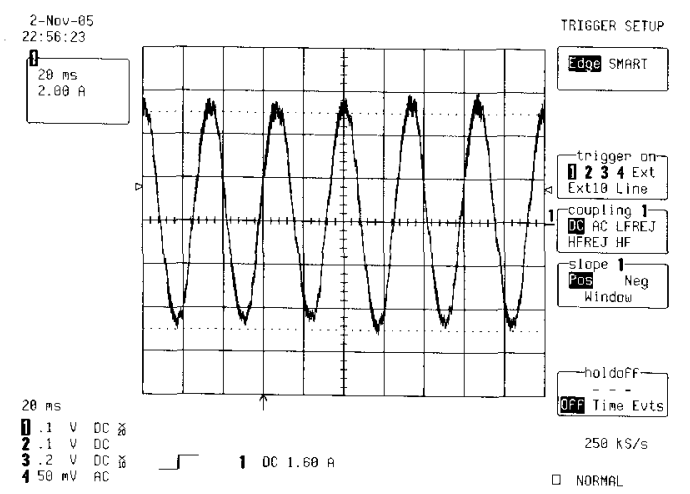

(a) Phase current waveform

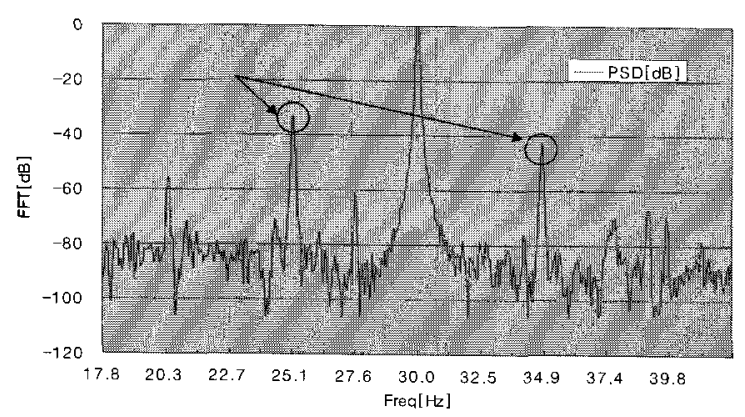

(b) PSD results of phase current

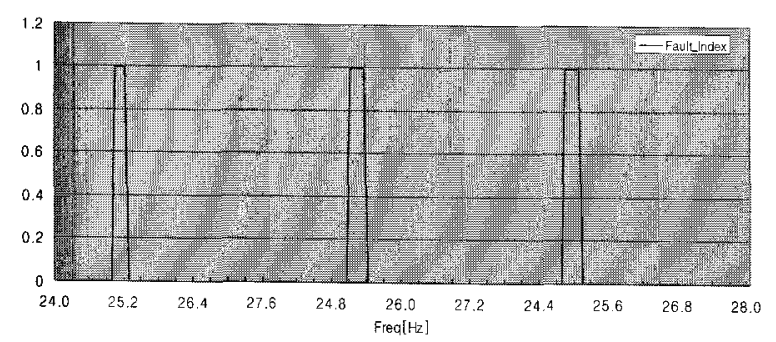

(c) Fault signal with the proposed algorithm

Fig. 5. Experimental results
Table 1. Induction motor parameters

\begin{tabular}{|c|c|c|c|}
\hline Rated power & $3 \mathrm{Hp}$ & Rated speed & $1760 \mathrm{rpm}$ \\
\hline Rated voltage & $230 \mathrm{~V}$ & Rated current & $7.6 \mathrm{~A}$ \\
\hline
\end{tabular}

Fig. 5(a) represents current waveform of the rotor defect motor. Fig. 5(b) shows PSD result of a faulty motor, which has broken rotor fault current component abound $25 \mathrm{~Hz}$. As shown in this figure, rotor fault component is $36[\mathrm{~dB}]$ which means this induction motor has some problems in the rotor.

Fig. 5(c) indicates the results of current spectrums using the proposed algorithm, which is axis transformation and average method. As demonstrated in this result the proposed algorithm can detect bearing defect using 12 bit ADC. Table 1 presents the motor parameters that are used in this paper.

\section{Conclusion}

This paper has investigated the feasibility of detecting broken rotor faults using an axis transformation and speed estimation using look up table for the current spectrum of an inverter driven induction machine.

Induction motor defects caused by broken rotor faults produce visible changes in the stator current spectrum at predictable frequencies. However, it is very difficult to detect these using the FFT method because it takes a very long time and needs a significant amount of data information. Therefore, axis transformation and speed estimation instead of the FFT method have proved to be very effective and cost efficient through simulation and experimental results.

\section{References}

[1] G.B. Kliman, R.A. Koegl, J. Stein, R.D. Endicott, and M.W. Madden, "Noninvasive detection of broken rotor bars in operating induction motors," IEEE Trans. Energy Conv., vol. 3, pp. 873-879, Dec. 1988.

[2] R. Schoen, T. Habetler, F. Kamran, and R. Bartfield, "Motor bearing damage detection using stator current monitoring," IEEE Trans. Ind. Appl., vol. 31, no. 6, pp. 1274-1279, Nov./Dec. 1995.

[3] M.E.H. Benbouzid, "A review of induction motors signature analysis as a medium for faults detection," IEEE Trans. Ind. Electron., vol. 47, no. 5, pp. 984993 , Oct. 2000.

[4] S. Nandi, M. Bharadwaj, and H.A. Toliyat, "Performance Analysis of a Three-Phase Induction 
Motor Under Mixed Eccentricity Condition," IEEE Trans. Energy Conv., vol. 17, pp. 392-399, Sep. 2002.

[5] J.F. Watson, N.C. Paterson, and D.G. Dorrell, "The Use of Finite Element Methods to Improve Techniques for the Early Detection of Faults in 3phase Induction Motors", IEEE Trans. on Energy Conversion, vol. 14, No. 3, pp. 655-660, Sep. 1999.

[6] H.A. Toliyat, M.S. Arefeen, and A.G. Parlos, "A Method for Dynamic Simulation and Detection of Air-Gap Eccentricity in Induction Machines", IEEE Trans. on Industry Applications, vol. 32, No. 4, pp. 910-918, Jul./Aug. 1996.

[7] F. Filippetti, G. Franceschini, C. Tassoni, and P. Vas, "Recent developments of induction motor drives fault diagnosis using AI techniques," IEEE Trans. Ind. Electron., vol. 47, no. 5, pp. 994-1004, Oct. 2000.

[8] M. A. Awadallah and M. M. Morcos, "Application of AI tools in fault diagnosis of electrical machines and drives-an overview," IEEE Trans. Energy Convers., vol. 18, no. 2, pp. 245-251, Jun. 2003.

[9] J.-S. R. Jang, "ANFIS: adaptive-network-based fuzzy inference system," IEEE Trans. Syst., Man, Cybern., vol. 23, no. 3, pp. 665-685, May/Jun. 1993.

[10] McDermid, W., "Insulation systems and monitoring for stator winding of large rotating machines," IEEE Electrical Insulation Magazine, vol. 9, no. 4, pp. 715, 1993.

[11] Schemp, D.E., "Predict motor failure with insulation testing," Plant Engineering, vol. 50, pp. 97-96, 1996.

[12] Stone, G.C., "Partial discharge measurements to access rotation machine insulation condition: A survey," Conference Record of the IEEE International Symposium on Electrical Insulation, pp. 19-23, 1996.

[13] J.R. Cameron, W. T. Thomson and A.B. Dow, "Vibration and Current monitoring for detecting airgap eccentricity in large induction motors", Proceeding of IEE, vol. 133, Pt. B, No. 3, pp. 155163, May 1986.

[14] J. S. hsu, "Monitoring of defects in induction motors through air-gap torque observation," IEEE Transaction on Industrial Applications, Vol. 31, No. 5, pp. 1016-1021, Sept./Oct. 1995.

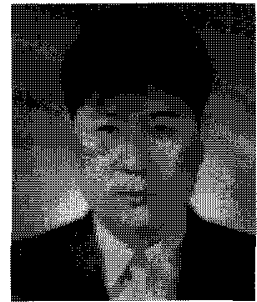

Namhun Kim

He received his B.S. degree in Control and Instrumentation Engineering from Samchuk National University, South Korea, in 1998, and his M.S. and Ph.D degrees in Electrical Engineering from Yeungnam University, South Korea, in 2000 and 2003, respectively. From 2004, he was a Post Doc. Researcher at Texas A\&M University, USA and now he is an Instructor at Cheongju University, South Korea. $\mathrm{He}$ is engaged in research on motor control and design, as well as fault diagnosis of electrical machines.

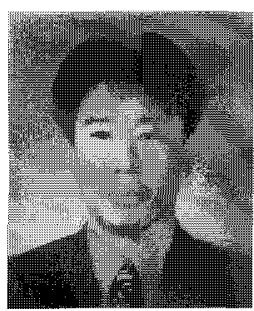

\section{Changho Choi}

He received his B.S. degree from Ajou University, Suwon, Korea in 1979, his M.S. degree from Seoul National University, Seoul, Korea, in 1984, and his Ph.D. degree from Hanyang University, Seoul, Korea, in 2000, all in Electrical Engineering. From 1983 to 1986, he was with the Research Institute of LG Industrial Systems Co., Ltd., Anyang, Korea, where he was a Senior Researcher in the Department of Power Electronics. From 1987 to 1990, he was with Korea Servo Corporation, Suwon, Korea, as a Principal Researcher in the Department of Servo Motor Drives. Since 1990, he has been with the Department of Power Electronics as a Chief Researcher, R\&D Center of POSCON Corporation, Seoul, Korea. His current research interests are high-power motor drive systems for continuous processing lines, power quality systems, highvoltage pulse power applications, and energy saving systems. 